\title{
Radial Keratotomy: 500 Consecutive Cases
}

\author{
W. J. JORY \\ London
}

\begin{abstract}
Summary
A report on 500 consecutive eyes having radial keratotomy for myopia and myopic astigmatism is presented. Surgery was on an out-patient basis under local anaesthetic, with a follow-up of $99.2 \%$ of cases, $91.8 \%$ of the 294 patients elected to have radial keratotomy on the fellow eye. The surgical protocol was designed to minimise side effects and complications rather than maximise the reduction in myopia. 6/12 unaided vision or better was achieved by $99 \%$ of cases in the low myopia group, $91 \%$ in the middle and $41 \%$ in the high myopia group. Persistent hypermetropia of $+1.00 \mathrm{D}$ or greater occurred in only $0.4 \%$ of cases and secondary astigmatism of $1.00 D$ or greater in $1 \%$ of cases. Corneal perforations were minimised by single-pass incisions, but this was at the cost of lesser myopic corrections in the higher myopic group. Centering on the visual axis rather than the centre of the pupil minimised glare sensitivity. No patient developed potentially blinding complications.
\end{abstract}

\section{Selection of Patients}

Patients were selected on the following criteria:

(1) Lower age limit was 18 years, there was no upper limit for the surgery.

(2) The refraction was stable.

(3) There was no active external ocular disease.

(4) Physiological myopia was present without the ophthalmoscopic signs of progressive pathological myopia.

(5) Candidates were either intolerant of contact lenses or required reduction or abolition of their refractive error for occupational reasons or because of sporting activities.

(6) Amblyopic eyes were accepted.

(7) Patients were informed of the advantages and disadvantages of radial keratotomy.

(8) Patients were counselled on the possible side effects and complications of radial keratotomy.

(9) Patients were given an estimate of the likely visual and dioptric results of the surgery.

(10) Although many patients were seen direct, they were encouraged to visit their general practitioner before attending the centre. Consultation reports were sent to general practitioners before treatment together with an account of radial keratotomy, and an operation report on the day of surgery. A final report was sent on completion of treatment.

\section{Technique of radial keratotomy}

(1) All surgeries were done on an out-patient basis in a sterile operating theatre and using sterile surgical techniques.

(2) Surgery was done using an operating microscope.

(3) Pre-medication of $10 \mathrm{mg}$ valium was given orally.

(4) Surgery was done on the non-dominant eye first followed by the fellow eye approximately six weeks later.

Correspondence to: London Centre for Refractive Surgery, 21 Devonshire Place, London W1N 1PD. 
(5) The amount of surgery was planned by nomogram based on patient's age and refractive error.

(6) Ultrasonic pachymetry to determine corneal thickness was performed immediately preoperatively.

(7) The eye was anaesthetised with Guttae Amethocaine 1\%.

(8) The eye was kept minimally moist with sterile normal saline during the surgical procedure.

(9) Great care was taken to mark the intersection of the visual axis on the cornea.

(10) Dull marking trephines with cross hairs and $3.00,3.25,3.50,3.75,4.00,4.50,5.00$ and $6.00 \mathrm{~mm}$ diameters were used.

(11) Radial incisions were done with a singleedged $45^{\circ}$ angle diamond blade set at $115 \%$ of the average para-central corneal depth measured by ultra-sonic pachmetry, aiming to achieve between $90 \%$ and $95 \%$ depth at the commencement of the radial incisions. Incisions were centrifugal, i.e. from optical zone to periphery. The ultrasonic probe was placed exactly on the optical (clear) zone mark in the position of the radial incisions.

(12) Transverse incisions were done with a double-edged diamond blade.

(13) Diamond blades were set in micrometer handles and calibrated with a blade guage.

(14) Both eyes of the same patient were done with the same blade.

(15) Incisions were thoroughly irrigated with normal saline at the conclusion of the surgery. (16) Guttae Gentamycin and Guttae Cyclogyl $1 \%$ were instilled in the operated eyes.

(17) The eye was lightly patched for three hours only.

(18) Post-operative pain was controlled with tablets DF118 for 12 to 18 hours only.

(19) Guttae Maxitrol was instilled post-operatively twice a day for two weeks.

(20) Follow-up was at two weeks and again at the two weeks after the second operation and requested at six months and one year. No patients have been discharged from care.

The standard interval between eyes having surgery was six weeks, and between primary and secondary surgery on the same eye was between three and six months.

\section{Study Population}

Five hundred consecutive eyes had radial or radial and transverse keratotomy. Secondary surgery was performed on 54 eyes or $10.8 \%$ of the total (PERK 9\%). The total number of patients treated was 294, of which: $194(66 \%)$ were males (PERK 52\%) and $100(34 \%)$ females (PERK 48\%). Follow up was possible in 496 out of the 500 cases $(99.2 \%)$. Maximum follow-up was two years. Out of 294 patients, $270(91.8 \%)$ elected to have radial keratotomy on the fellow eye. (Some of these cases are not included in the 500 consecutive keratotomies described here). Seven patients had planned uniocular surgery. At baseline the spherical equivalent refraction was (i) $-1.00 \mathrm{D}$ to $-3.00 \mathrm{D}$ in 127 eyes (plus two not followed up and therefore excluded). Eighty nine of these had radial keratotomy and 38 had radial and transverse keratotomy. (ii) $-3.25 \mathrm{D}$ to $-6.00 \mathrm{D}$ in 211 eyes with 153 patients having radial keratotomy and 58 having radial and transverse keratotomy. (iii) $-6.25 \mathrm{D}$ to $-9.00 \mathrm{D}$ in 117 eyes (plus two eyes not followed up and therefore excluded). One hundred and one cases had radial keratotomy and 16 had radial and tranverse keratotomy. (iv) over $-9.00 \mathrm{D}$ in 45 eyes.

Some of the reasons given for wanting keratotomy surgery included: (i) intolerance of contact lenses.

(ii) Fear of losing glasses or contact lenses in an emergency.

(iii) Thickness and weight of glasses.

(iv) Inability to participate in outdoor activities particularly swimming but also other sports i.e. mountaineering and skiing.

(v) Improvement of unaided visual acuity to meet occupational requirements.

(vi) No surgery was done for cosmetic reasons only.

\section{Visual results}

The visual results are expressed as a percentage of $6 / 12$ uncorrected visual acuity since it is considered that this is the most meaningful statistic to present to the patient considering radial keratotomy surgery. Average predicted result or average dioptric result gives a less meaningful forecast to the patient. The percentage of patients achieving emmetropia is not used, since for reasons described later, it is not always desirable to aim for this. Success of the surgery as defined by the International 
Society of Refractive Keratoplasty is 6/12 (20/ 40) unaided vision. ${ }^{2}$

In the low myopia group of $-1.00 \mathrm{D}$ to $-3.00 \mathrm{D}, 125$ eyes out of 127 achieved 6/12 unaided vision or better. Of the remaining two cases, one had 4 cylinder pre-operatively and one case was amblyopic.

In the group of moderate myopia of $-3.25 \mathrm{D}$ to $-6.00 \mathrm{D}, 211$ eyes had surgery. One hundred and eighty-six out of the 211 eyes achieved $6 / 12$ vision unaided or better.

In the high myopia group of $-6.25 \mathrm{D}$ to $-9.00 \mathrm{D}, 117$ eyes had surgery, forty-five of these achieved $6 / 12$ vision or better unaided following surgery.

In the very high myopia group of greater than $-9.00 \mathrm{D} 45$ eyes had surgery. Every eye achieved a significant and major reduction in the myopic spherical equivalent.

Most refractions were stable at between one and two months and $5 \%$ of cases continued to decay up to the sixth month gate and three eyes to the one year gate.

The surgical plan was slightly conservative in the surgery on the first eye and used the experience of the response of that eye in planning the operation on the second eye. Thus most of the secondary surgery was done on the first eye. It was found that the response of the second eye could be predicted accurately from the response of the first eye.

Table I lists the results of post-operative unaided visual acuity and where there has been decay of effect up to 12 months the results are corrected accordingly. There was no decay of effect after the 12th month gate.

Table II lists the results of this study with other comparable ones. ${ }^{1,3,4,5,6}$ However it should be noted that only the United States studies used independent examiners for the measurement of visual acuity and refraction. The studies are comparable although there is some difference in the parameters of the groups of myopes. To assist in the comparison, amblyopic eyes in this study have been excluded in the visual results as they were in other studies.

\section{Complications}

Post-operative complications are divided into three groups as in the PERK Report.

(1) Transient signs and symptoms.
(2) Persistent signs and symptoms that did not reduce best corrected visual acuity.

(3) Complications that actually or potentially reduced visual acuity.

\section{(1) Transient Signs and Symptoms}

Ocular pain often described as similar to toothache in the eye was common but was usually controlled by oral analgesics such as DF118. Pain was nearly always better by the following day and was eased on the day of surgery by removal of the eye patch. Many patients described a slightly scratched feeling in the eye for two weeks post surgery after which it gradually subsided. Pain was usually more severe when an increased number of incisions had been made or where the corneal epithelium had tended to strip off during the incision. Very little conjunctival injection was caused by this surgery.

Fluctuation of vision more properly described as variation of refraction, was reported by many patients especially during the first month but this decreased steadily. (Table III) The eye became more myopic during the day but only one patient has required two pairs of glasses (for day and evening wear). Variation of refraction probably occurs in all cases but is often not apparent to the patient. It is caused by the increased flexibility of the cornea during the healing period and is therefore more marked in the older patient with slower healing, particularly in the higher myopic group. The variation occurs as a response to diurnal changes in intraocular pressure and upper lid pressure during sleep. ${ }^{7}$

\section{(2) Persistent signs and symptoms that did not reduce corrected visual acuity. (Table IV).}

Initial hypermetropia of $+1.00 \mathrm{D}$ or greater occurred in five eyes out of $500(1 \%)$. If this persisted at one month Guttae Timolol Maleate $1 \%$ was administered twice a day to the hypermetropic eye. This resulted in the abolition of the hypermetropia in three of the eyes presumably by lowering the intraocular pressure, although it is possible that there was a decay in the surgical effect. Persistent hypermetropia occurred in two out of 500 eyes $(0.4 \%)$. The PERK Report recorded secon- 
Table I Post-operative unaided visual acuity

\begin{tabular}{|c|c|c|c|c|c|c|c|c|}
\hline $\begin{array}{l}\text { Myopia group } \\
\text { and surgery }\end{array}$ & $6 / 6$ & $6 / 9$ & $6 / 12$ & $6 / 18$ & $6 / 24$ & $6 / 36$ & $6 / 60$ & $6 / 60+$ \\
\hline \multicolumn{9}{|l|}{$\begin{array}{l}\text { 1. Low } \\
-1.00 \text { to }-3.00 \\
\text { (total } 127 \text { eyes) }\end{array}$} \\
\hline i. Radial K. (89 eyes) & $64(71.9 \%)$ & $19(21.5 \%)$ & $4(4.5 \%)$ & $1(1.0 \%)$ & $1(1.0 \%)$ & & & \\
\hline $\begin{array}{l}\text { ii. Radial and Transverse } \\
\text { K. ( } 38 \text { eyes) }\end{array}$ & $13(34.2 \%)$ & $15(39.5 \%)$ & $8(21.0 \%)$ & $1(2.6 \%)$ & $1(2.6 \%)$ & & & \\
\hline \multicolumn{9}{|l|}{$\begin{array}{l}\text { 2. Middle } \\
-3.25 \text { to }-6.00 \mathrm{D} \\
\text { (total } 211 \text { eyes) }\end{array}$} \\
\hline i. Radial K. 154 eyes) & $58(38 \%)$ & $54(34.6 \%)$ & $25(17.6 \%)$ & $7(4.6 \%)$ & $3(2.0 \%)$ & $2(1.3 \%)$ & $4(2.6 \%)$ & \\
\hline $\begin{array}{l}\text { ii. Radial and Transverse } \\
\text { K. ( } 57 \text { years) }\end{array}$ & $19(33.3 \%)$ & $15(26.3 \%)$ & $15(26.3 \%)$ & $2(3.5 \%)$ & $6(10.5 \%)$ & & & \\
\hline \multicolumn{9}{|l|}{$\begin{array}{l}\text { 3. High } \\
-6.25 \text { to }-9.00 \\
\text { (total } 117 \text { eyes) }\end{array}$} \\
\hline i. Radial K. (101 eyes) & $6(6.0 \%)$ & $9(8.9 \%)$ & $22(21.8 \%)$ & $10(9.9 \%)$ & $10(9.9 \%)$ & $13(12.8 \%)$ & $17(16.8 \%)$ & $14(13.9 \%)$ \\
\hline $\begin{array}{l}\text { ii Radial and Transverse } \\
\text { K. ( } 16 \text { eyes) }\end{array}$ & $3(18.8 \%)$ & $1(6.2 \%)$ & $4(25.0 \%)$ & $1(6.2 \%)$ & $4(25 \%)$ & & & $3(18.8 \%)$ \\
\hline
\end{tabular}

Total: 455 eyes ( 15 amblyopic eyes at less than $6 / 12$ included, 45 eyes at greater than -9.00 excluded)

dary hypermetropa of $11 \%$ in the lower myopic group, $12 \%$ in the middle myopic group and $6 \%$ in the higher myopic group.

Five eyes in the study of 500 eyes $(1 \%)$ developed secondary astigmatism of $1.00 \mathrm{D}$ or greater. This compares with $9.5 \%$ in the PERK Report and Percival ${ }^{3}$ reporting 5\% secondary astigmatism. Secondary astigmatism can be caused by uneven spacing of the incisions and variations in depth achieved and is probably aggravated by re-incising the primary incisions.

Epithelial 'pearls' or inclusion cysts and other debris in the scars occurred in only two incisions in the series. These were probably due to inadequate irrigation of the wounds with normal saline at the conclusion of the surgery. Such inclusions can cause delay in wound healing ${ }^{8}$ and may become a site for late keratitis. ${ }^{9}$ They can be dissected out under local anaesthetic post-operatively.

Epithelial iron lines were common ${ }^{10}$ but often very difficult to see and tended to occur at one year post-operatively or later. Iron lines may be related to changes in corneal curvature. They are more frequent in high myopic corrections and are possibly due to the deposition of iron from tear pooling ${ }^{11}$ but they do not affect visual acuity.

(3) Complications that actually or potentially reduced visual acuity (Table V)

A decrease in the best visual acuity of more than one line occurred in nine patients

Table II Comparison studies of post-operative unaided visual acuity (amblyopic eyes excluded)

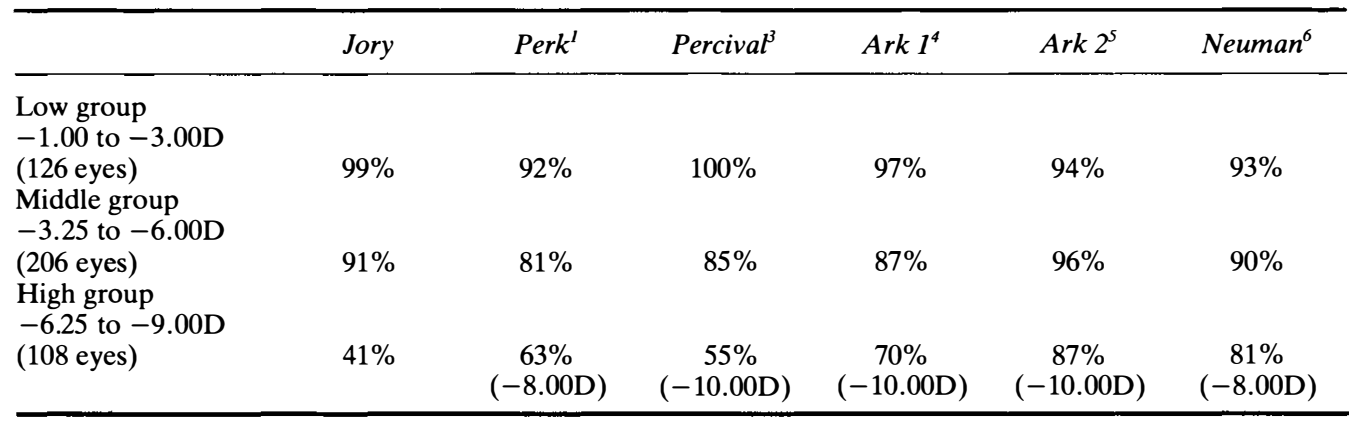


Table III Disabling variation of refraction (fluctuation)

\begin{tabular}{llrll}
\hline At & 2 Weeks & 30 & $=$ & $6.0 \%$ \\
& 1 Month & 24 & $=$ & $4.8 \%$ \\
& 2 Months & 20 & $=$ & $4.0 \%$ \\
3 Months & 14 & $=$ & $2.8 \%$ \\
& 4 Months & 8 & & \\
6 Months & 4 & & \\
1 Year & 2 & \\
\hline
\end{tabular}

(1.8\%), PERK reporting $13 \%$ and Percival $3 \%$ having such a reduction. On the other hand, 15 eyes (3\%) had an increase in best visual acuity. There were no macular changes noted which would have been caused by the microscope light during surgery ${ }^{12}$ and these variations may be due to mild irregular astigmatism.

Macro-perforations cause wound gape, loss of anterior chamber and require suturing, however there were none in this series. Microperforations occurred in seven cases $(1.4 \%)$ but none of these required suturing, all anterior chambers were maintained and surgery was completed in every case. PERK reported $2.9 \%$ micro-perforations, Arrowsmith $35 \%$ and Deitz ${ }^{4} 36 \%$ micro-perforations in their first studies, later reducing to $7 \%{ }^{5}$ in their second studies. Of the seven cases of micro-perforation in this series, three were due to incorrect calibration of a new knife and blade, three occurred in inferior transverse keratotomy incisions and one occurred in a radial incision probably as a result of crossing an uncharted posterior corneal dimple.

Epithelial basement changes ${ }^{13}$ and erosions such as map fingerprint occurred in the epithelial basement membrane in two cases but these resolved at two months. There were no cases of corneal epithelial erosions. Such corneal erosions can occur where incisions cross on the cornea.

Post-operative Trauma. There were four cases of trauma occurring in the first month post-operatively. One patient experienced a continued and violent sneezing episode between one and two hours post-operatively. The intraocular pressure in such episodes has been calculated to increase considerably. ${ }^{14}$ The patient had had 16 radial keratotomy incisions and returned on the next day with a flat anterior chamber which eventually resulted in suturing of three of the wounds. This induced some corneal scarring and was one of the five cases of secondary astigmatism. The patient's other eye with similar surgery six weeks previously remained intact. This episode demonstrates the increase in wound strength at six weeks. Two patients were forcibly poked in the eye on the day of surgery causing intense pain and the fourth patient travelling on his motorbike at $80 \mathrm{mph}$ on the M1 motorway somersaulted several times after being thrown off. The accident occurred one month post-operatively. All four cases have a corrected visual acuity of $6 / 6$ and the last three cases maintained the integrity of their radial keratotomy incisions.

Glare sensitivity is subjective and it is very difficult to evaluate although some investigators have used glare testers. ${ }^{15}$ It can be said to be common in the first two weeks, uncommon at three months and occasional at one year. All patients were asked to report this at post-operative examination but few complained about glare after two weeks and only two patients reported reducing their night driving. Persistent glare can be minimised by ensuring that the visual zone is centred on the visual axis rather than on the centre of the pupil. ${ }^{16}$ The radial incisions must be perpendicular to the cornea and not slanted, particularly at the visual zone margin, they should not be deepened by a second pass of the knife and must be thoroughly irrigated.

Flare is common with the patient seeing the central ends of the incisions which pick up light at night against a dark background. However few patients complain of this after first noting it and it is gradually ignored.

Specular microscopy had previously documented endothelial cell loss of between $5 \%$ and $8 \%{ }^{17,18}$ This is in line with other studies $^{19,20}$ and its measurement had been discontinued prior to this series.

Potentially blinding complications. No

Table IV Persistent refractive complications

\begin{tabular}{lccc}
\hline & Jory & Perk & Percival \\
\hline $2^{\circ} \begin{array}{l}\text { Hypermetropia } \\
+1.00 D \text { or more }\end{array}$ & $0.4 \%$ & $10.0 \%$ & N.R. \\
$\begin{array}{l}\text { 2 } \\
\begin{array}{l}\text { Astigmatism } \\
+1.00 D \text { or more }\end{array}\end{array}$ & $1.0 \%$ & $9.5 \%$ & $3.0 \%$ \\
\hline
\end{tabular}


Table V Complications that actually or potentially reduced visual acuity

\begin{tabular}{lllccc}
\hline & Jory & Perk & Percival & Art 1 & Art 2 \\
\hline \% Reduced V.A. & $1.8 \%$ & $13 \%$ & $3 \%$ & NR & $0.3 \%$ \\
Microperforations & $1.4 \%$ & $2.9 \%$ & NR & $35 \%$ & $7 \%$ \\
Corneal erosions & $0 \%$ & $1 \%$ & NR & $0 \%$ & $0 \%$ \\
Delayed bacterial keratitis & $0 \%$ & $2 \%$ & NR & NR & $1 \%$ \\
Other potentially blinding & $0 \%$ & $0 \%$ & $0 \%$ & $0 \%$ & $0 \%$ \\
\hline
\end{tabular}

patient developed keratitis, uveitis, cataract or endophthalmitis. One patient developed steroid-induced glaucoma which subsided on the cessation of the Guttae Maxitrol being used post-operatively. It was interesting to note the enhanced effect of the surgery with the raised intraocular pressure which then diminished when the glaucoma was brought under control. No maculopathy was observed from the use of the operating microscope and its bright illumination. The rule was observed to make the incisions slowly and perform the operation quickly, both to guard against such maculopathy and also corneal thinning which would negate the accuracy of the ultra-sonic pachymetry.

\section{Discussion}

All patients obtained a significant and worthwhile reduction in their myopia. The best results occurred in the lower and middle myopia groups with over $99 \%$ and $91 \%$ success rate respectively, but provided patients were advised of the likely outcome of their surgery those in the high myopia groups were just as pleased with the substantial reduction in the myopia as those who had had their myopia abolished. Although there was a better than $99 \%$ follow-up post-operatively the percentage of long term follow-up at six months and one year was less than the other studies quoted. This reflects the much wider geographic origin of patients in this study. Nevertheless, the visual results in the lower two myopia groups compare well with the other studies published ${ }^{1,3,4,5,6}$ but it is significant that the reduction in myopia in the higher groups was not as great. This was almost certainly due to the policy of not reincising primary incisions to avoid increasing the incidence of micro-perforations. Glare was minimised by single pass incisions and the care was taken to centre all surgery upon the visual axis and not on the centre of the pupil. The presence of a large angle alpha becomes particularly important when operating on a visual zone of only $3.00 \mathrm{~mm}$. It must be emphasised that total predictability of results ${ }^{21,22}$ still eludes the surgeon who is doing radial keratotomy surgery although results are improving. ${ }^{23}$ This almost certainly relates to variable healing response due to individual biological variation ${ }^{24}$ with some patients under responding and others over responding to surgery. This is a problem with all invasive surgical procedures for the correction of refractive error whether by blade or by laser.

No cases of infection occurred during this series. There have been isolated reports in the literature of delayed bacterial keratitis and these are thought to be due to epithelial inclusions in the wounds. Such inclusions are minimised by meticulous irrigation of the wounds at the completion of surgery. Prolonged firm patching post-operatively can cause epithelial downgrowth into the wounds and should be avoided. The low frequency of infection reported in all studies of radial keratotomy compares very favourably with the relatively high incidence of severe corneal infection from the use of sof $\mathrm{t}^{25}$ and extended wear contact lenses. ${ }^{26,27,28,29}$

There is no evidence that radial keratotomy permanently weakens the eye. Nevertheless, all surgical wounds take time to gain strength particularly in the vascular cornea. ${ }^{30}$ Only isolated cases of traumatic radial keratotomy wound dehiscence have been reported, ${ }^{31,32}$ whilst other reports have demonstrated wound integrity even when scleral rupture has occurred. ${ }^{33}$ Larsen $^{34}$ reported $33 \%$ optic nerve evulsions in his control group and only $2 \%$ in his radial keratotomy group. The corneal incisions appear to act in some protective way against more serious injury. This is probably due to increased flexibility of the radial 
keratotomy cornea caused by the surgical interruption of the long collagen fibrils embedded in the corneal matrix which control corneal flexing as do carbon fibre rods in a fibreglass yacht hull.

\section{Conclusions}

Radial keratotomy achieves a worthwhile visual improvement in virtually all myopic patients. ${ }^{35}$ Side effects such as glare and variation of refraction can be reduced by careful surgery. ${ }^{36}$ Severe complications are very rare. ${ }^{37}$ The visual benefits must be balanced against the refractive side effects of possible secondary astigmatism, secondary hypermetropia from over correction and the effects of the onset of presbyopia. ${ }^{38,39,40,41}$ Ten years ago, radial keratotomy was considered an experimental procedure. It has now been proved effective in reducing myopia in both clinical and laboratory studies and its potential implications have been well delineated. Therefore the International Society of Radial Keratoplasty no longer considers it either experimental or investigative ${ }^{2}$ and it is now widely practiced by eye surgeons around the world.

Radial keratotomy is a stepping stone on the pathway of refractive surgery. ${ }^{42,43,44,45,46}$ Other surgical procedures include epikeratophakia which unfortuntely has a tendency towards regression of effect, ${ }^{47,48}$ polysulfone

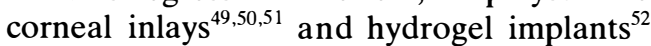
and the use of the Excimer laser for sculpting the cornea. ${ }^{53,54,55}$ All of these methods are in their early stages of development and testing and will not be available for regular clinical use for several years. It is important to keep an open mind on all these procedures rather than championing one against the others; the sum of our corneal knowledge is increased by them all. It may well be that we will progress to synthetic epikeratophakia ${ }^{56}$ as an additive procedure and corneal sculpting with the Excimer Laser as a subtractive one. ${ }^{57}$ All surgical procedures involve wound healing to some degree and total predictability will still be a problem in these more sophisticated operations. ${ }^{58}$ Experiments so far with wound healing modifiers have been disappointing. ${ }^{59,60}$
Radial keratotomy is currently the most tested $^{61}$ and widely-used procedure in our progress to a world without glasses.

\section{References}

${ }^{1}$ Waring GO, Lynn MJ, Gelender H, et al.: Results of Prospective Evaluation of Radial Keratotomy (PERK) Study one year after Surgery. Ophthalmology 1985, 92: 177-96.

${ }^{2}$ Board of Directors of International Society of Refractive Keratoplasty. Statement on radial keratotomy in 1988. J Refract Surg 1988, 3: 80-90.

${ }^{3}$ Percival SPB: Radial keratotomy: Where did it go Wrong? Eye 1988, 2: 478-83.

${ }^{4}$ Arrowsmith PN, Sanders DR, Marks RG: Visual, refractive and keratometric results of radial keratotomy. Arch Ophthalmol 1983, 101: 873-81.

${ }^{5}$ Deitz MR, Sanders DR, Marks RG: Radial keratotomy: An overview of the Kansas City study. Opthalmology 1984, 91: 467-77.

${ }^{6}$ Neuman AC, Osher RH, Fenzel RE: Radial keratotomy: A clinical and statistical analysis. Cornea 1983, 2: 47-55.

${ }^{7}$ Schanzlin DJ, Santos VR, Waring GO, et al.: Diurnal change in refraction, corneal curvature, visual acuity and intraocular pressure after radial keratotomy in the PERK study. Ophthalmology 1986, 93: 167-75.

${ }^{8}$ Mandelbaum S, Waring GO, Forster RK, et al.: Late development of ulcerative keratitis in radial keratotomy scars. Arch Ophthalmol 1986, 104: 1156-60.

${ }^{9}$ Shivitz IA and Arrowsmith PN: Delayed keratitis after radial keratotomy. Arch Ophthalmol 1986, 104: 1153-5.

10 Steinberg EB, Wilson LA, Waring GO, et al.: Stellate iron line in the corneal epithelium after radial keratotomy. Am J Ophthalmol 1984, 98: 416-21.

${ }^{11}$ Davis RM, Miller RA, Lindstrom RL, et al.: Corneal iron lines after radial keratotomy. $J$ Refract Surg 1986, 4: 174-8.

${ }^{12}$ Menezo JL, Harto MA, Cisneros AL: Light-induced maculopathy from the operating microscope in radial keratotomy. J Refract Surg 1988, 5: 179-82.

${ }^{13}$ Nelson JD, Williams P, Lindstrom RL, et al.: Mapfingerprint dot changes in the corneal epithelial basement membrane following radial keratotomy. Ophthalmology 1985, 92: 199-205.

${ }^{14}$ Bain, Maurice. Physiological variations in the intraocular pressure. Trans Ophthalmol Soc UK 1959, 79: $249-60$.

${ }^{15}$ LeClaire J, Nadler MP, Weiss S, et al.: A new glare tester for clinical testing: results comparing normal subjects and variously corrected aphakic patients. Arch Ophthalmol 1982, 100: 153-8.

${ }^{16}$ Waring GO: Evolution of radial keratotomy for Myopia. Trans Ophthalmol Soc UK 1984, 104: 28-42.

${ }^{17}$ Chiba K, Oak SS, Tsubota K, et al.: Morphometric analysis of corneal endothelium following radial keratotomy. J Cat Refract Surg 1987, 13: 263-7. 
${ }^{18}$ McRae SM, Matsuda M, Rich LF: The effect of radial keratotomy on the corneal endothelium. Am J Ophthalmol 1985, 100: 538-42.

${ }^{19}$ Bores LD: Historical review and clinical results of radial keratotomy, in Binder PS (ed.) Refractive corneal surgery: The correction of aphakia, hyperopia and Myopia. Int Ophthalmol Clin 1983, 23: 93-118.

${ }^{20}$ Waring GO, Laibson $\mathrm{P}$, Lindstrom $\mathrm{R}$ et al.: Changes in refraction, keratometry and visual acuity during the first year after radial keratotomy in the PERK Study. Invest Ophthalmol Vis Sci 1985; 26 (suppl): 202.

${ }^{21}$ Arrowsmith PN and Marks RG: Evaluating the predictability of radial keratotomy. Ophthalmology 1985, 92: 331-8.

${ }^{22}$ Sander DR, Deitz MR, Gallagher.D: Factors affecting the predictability of radial keratotomy. Ophthalmology 1985, 92: 1237-43.

${ }^{23}$ Lynn MJ, Waring GO, Sperduto RD, et al.: Factors affecting outcome and predictability of radial keratotomy in the PERK study. Arch Ophthalmol 1987, 105: 42-51.

${ }^{24}$ Journal of Refractive Surgery 1988, 4: 37-45.

${ }^{25}$ Binder PS: Complications associated with extended wear of contact lenses. Ophthalmology 1979, 86: 1093-101.

${ }^{26}$ Graham CM, Dart JKG, Buckley RJ: Extended wear hydrogel and daily wear hard contact lenses for Aphakia. Success and complications in a longitudinal study. Ophthalmology 1986, 93: 1489-94.

${ }^{27}$ Graham CM, Dart JKG, Wilson-Holt NW, Buckley RS: Prospects for contact lens wear in aphakia. Eye 1986, 2: 48-55.

${ }^{28}$ Laibson PR and Donnenfeld ED: Corneal ulcers related to contact lens use. International Ophthalmology Clinics 1986, 26: 3-14.

${ }^{29}$ Franks WA, Adams GGW, Minassian D: Contact lens related disease in an ophthalmic casualty department and the increased risk of soft lens wear. $B$ Med $J$ (in press).

${ }^{30}$ Binder PS, Nayak SK, Deg JK, et al.: An ultrastructural and histochemical study of long-term wound healing after radial keratotomy. Am J Ophthalmol 1987, 103: 432-40.

${ }^{31}$ Simons KB, Linsalata RP: Ruptured globe following blunt trauma after radial keratotomy. A case report. Ophthalmology 1987, 94 (suppl): 148.

${ }^{32}$ Spivack L: Case report. Radial keratotomy incisions remain intact despite facial trauma for plane crash. J Refract Surg 1987, 3: 59-60.

${ }^{33}$ Fortstot SL and Damiamo RE: Trauma after radial keratotomy. Ophthalmology 1988, 95: 833.

${ }^{34}$ Larson BC, Kremer FB, Eller AW, et al.: Quantitated trauma following radial keratotomy in rabbits. Ophthalmology 1983, 90: 660-7.

${ }^{35}$ Waring GO: The changing status of radial keratotomy for myopia. Part II. J Refract Surg 1985, 1: 119-37.

${ }^{36}$ Hofman RF: Reoperations after radial and astigmatic keratotomy. J Refract Surg 1987, 3: 119-28.

${ }^{37}$ Steele ADM: The case for radial keratotomy. Optician May 1986, 23-7.
${ }^{38}$ Deitz MR and Sanders DR: Progressive hyperopia with long-term follow-up of radial keratotomy. Arch Ophthalmol 1985, 103: 782-4.

${ }^{39}$ Deitz MR, Sanders DR, Raanan MG: Progressive hyperopia in radial keratotomy. Long-term follow-up of diamond knife and metal blade series. Ophthalmology 1986, 93: 1284-9.

${ }^{40}$ Arrowsmith PN and Marks RG: Four-year update on predictability of radial keratotomy. $J$ Refract Surg 1988, 4: 37-45.

${ }^{41}$ Sawelson H and Marks RG: Five-year results of radial keratotomy. Refract Corneal Surg 1989, 1: 8-20.

${ }^{42}$ Bates WH: A suggestion of an operation to correct astigmatism. Arch Ophthalmol 1894, 23: 9-13.

${ }^{43}$ Lans LJ: Experimentelle Untersuchungen Uber Entstheung von Astigmatissus Durch Nicht-Perforirende Corneawunden. Albreght von Graefes' Arch Ophthalmol 1898, 45: 117-52.

${ }^{44}$ Sato T, Akiyama K, Shibata H: A new surgical approach to Myopia. Am J Ophthalmol 1953, 36: 823-9.

${ }^{45}$ Fyodorov SN and Durnev VV: Operation of dosaged dissection of the corneal circular ligament. Ann Ophthalmol 1979, 11: 1885-90.

${ }^{46}$ Yenaliev FS: Experience in the surgical treatment of Myopia. Vestn Ofthalmol 1979, 3: 52-5.

${ }^{47}$ Schlichtemeier WR, Arbegast KD: Long-term loss of effect of Myopic Epikeratophakia. J Refract Surg 1987, 2: 46-9.

${ }^{48}$ Frangieh GT, Wagoner MD, Steinert R: Refractive regression following Myopic Epikeratoplasty. Invest Ophthalmol Vis Sci 1988, 29: 311.

${ }^{49}$ Choyce DP: The correction of refractive error with polysulfone corneal inlays. A new frontier to be explored? Trans Ophthalmol Soc UK 1985, 104: $332-42$.

${ }^{50}$ Choyce DP: Polysulfone corneal inlays to correct refractive errors. Cataract 1985, 2: 6-11.

${ }^{51}$ Lane SL, Cameron JD, Lindstrom RL, et al.: Polysulfone corneal lenses. J.Catar Refract Surg 1986, 12: $50-60$.

${ }^{52}$ Pettit D, McCarey BE, McDonald MB, et al.: Refractive results of hyperopic hydrogel intracorneal lens implantation in primate eyes. (Avro Abstract). Invest Ophthalmol Vis Sci 1987, 28 (suppl): 276.

${ }^{53}$ Marshall J, Trokel S, Rothery S, et al.: Photoablative reprofiling of the cornea using an excimer laser: Photorefractive keratectomy. Lasers in Ophthalmology 1986, 1: 21-48.

${ }^{54}$ L'Esperance FA, Taylor DM, Del Pero RA, et al.: Human excimer laser corneal surgery: A preliminary report. Ophthalmology 1988, 95 (suppl): 145.

${ }^{55}$ Taylor DM, L'Esperance FA, De Pero RA, et al.: Human excimer laser lamellar refractive keratotomy-A clinical study. Ophthalmology 1988, 95 (suppl): 145.

${ }^{56}$ Werblin TP, Peiffer RL, Patel AS: Synthetic keratophakia for the correction of aphakia. Ophthalmology 1987, 94: 926-34.

${ }^{57} \mathrm{McDonald}$ MB: The future direction of refractive surgery. J Refract Surg 1988, 5: 158-68. 
${ }^{58}$ Aron-Rosa DS, Boerner CF, Bath P, et al.: Corneal wound healing after excimer laser keratotomy in a human eye. Am J Ophthalmol 1987, 103: 454-64.

${ }^{59}$ Kandarakis AS, Page C, Kaufman HE: The effect of epidermal growth factor on epithelial healing after penetrating keratoplasty in human eyes. $\mathrm{Am}$ J Ophthalmol 1984, 98: 411-5.
${ }^{60}$ Busin M, Yau C-W, Yamaguchi T, et al.: The Effect of Collagen Cross-Link Inhibitors on Rabbit Corneas after radial keratomy. Invest Ophthalmol Vis Sci 1986, 27: 1001-5.

${ }^{61}$ Waring GO: Development and evaluation of refractive surgical procedures. J Refract Surg 1987, 4: 142-57. 